\title{
The Phenylacetic Acid Uptake System of Aspergillus nidulans is under a creA-Independent Model of Catabolic Repression which Seems to be Mediated by Acetyl-CoA
}

\author{
José M. FernáNDEZ-CaÑón and José M. LuengGo* \\ Departamento de Bioquímica y Biología Molecular, Facultad de Veterinaria, Universidad de León, \\ León 24007, España
}

(Received for publication July 16, 1996)

\begin{abstract}
The filamentous fungus Aspergillus nidulans is able to grow on phenylacetic acid ( $\mathrm{PhAc}$ ) as the sole carbon source and has a highly specific phenylacetic acid transport system mediating the uptake of this aromatic compound. This transport system is also able to transport some phenoxyacetic acid ( $\mathrm{PhOAc}$ ), although less efficiently. Maximal uptake rates were observed at $37^{\circ} \mathrm{C}$ in $50 \mathrm{~mm}$ phosphate buffer ( $\mathrm{pH}$ 7.0). Under these conditions, uptake was linear for at least 1 minute, with $K m$ values for PhAc and PhOAc of 74 and $425 \mu \mathrm{M}$, respectively. The PhAc transport system is strongly induced by PhAc and, to a lesser extent by PhOAc and other phenyl derivatives. The utilization of glucose (and other sugars), glycerol or acetate results in a substantially reduced uptake. This negative effect caused by certain carbon sources is independent of the creA gene, the regulatory gene mediating carbon catabolite repression. Negative regulation by acetate is prevented by a loss-of-function mutation in the gene encoding acetyl-CoA synthetase, strongly suggesting that this regulation is mediated by the intracellular pool of acetyl-CoA.
\end{abstract}

The last step in the biosynthetic pathway of penicillin $\mathrm{G}$ (benzylpenicillin) and penicillin $\mathrm{V}$ (phenoxymethylpenicillin) in the filamentous fungi Penicillium chrysogenum and Aspergillus nidulans involves at least three different reactions: (i) uptake of aromatic compounds to be incorporated as the penicillin-side chain; (ii) activation of these molecules to CoA thioesters and (iii) exchange of the $\mathrm{L}-\alpha$-aminoadipic moiety present in the isopenicillin N (IPN) molecule by phenylacetic (penicillin G) or phenoxyacetic (penicillin V) acids (Fig. 1) ${ }^{1,2}$. It was believed that these aromatic compounds are only incorporated into the cell through a passive diffusion mechanism ${ }^{3)}$. However, we have demonstrated the existence of an active and inducible transport system responsible for the uptake of PhAc in P. chrysogenum ${ }^{4 \sim 6}$ and, more recently, in the bacterium Pseudomonas putida $^{7)}$. Some years later, Hillenga et al ${ }^{8)}$ proposed the existence in $P$. chrysogenum of a passive diffusion mechanism responsable for the cellular incorporation of this aromatic compound, whereas ERIKSEN et al. ${ }^{9}$, in the same fungus, showed the existence of an uptake system which has saturating kinetics as we had been reported. Although it is generally accepted that some aromatic compounds, containing a short acyl-chain, could cross the lipid bilayer to a certain extents by passive diffusion ${ }^{4,8 \sim 10)}$, this incorporation is not enough to assure cellular growth and, therefore, permeases should be needed for optimal growth in natural environments ${ }^{11}$.

The importance of the PhAc-transport system in the biosynthesis of certain hydrophobic penicillins together with the knowledge of the mechanisms controlling the uptake of this aromatic acid seemed to be very interesting in order to obtain further information about the regulation of secondary metabolites in fungi. We were therefore prompted to broaden our study to include A. nidulans. This fungus was selected as a model for three different reasons: a) Unlike $P$. chrysogenum, $A$. nidulans has a sexual cycle, which would facilitate genetic analysis; b) A. nidulans is able to grow in minimal medium containing $\mathrm{PhAc}$ as the sole carbon source even when the $\mathrm{pH}$ of the medium was 8.5 (suggesting the existence of a phenylacetic acid transport system) and c) $A$. nidulans, like $P$. chrysogenum, is able to synthesize penicillin $\mathrm{G}$ and $\mathrm{V}$. In summary, the study of the PhAc transport system in this fungus could be useful to clarify the implications of creA gene in the carbon catabolic regulation of this uptake, a point which remains obscure in $P$. chrysogenum and is one of the objectives of this work.

\section{Materials and Methods}

Materials

Phenyl derivatives were obtained from Aldrich Quimica (Madrid, Spain), Lancaster Synthesis Ltd. 
Fig. 1. Last three steps in the biosynthetic pathway of benzylpenicillin.

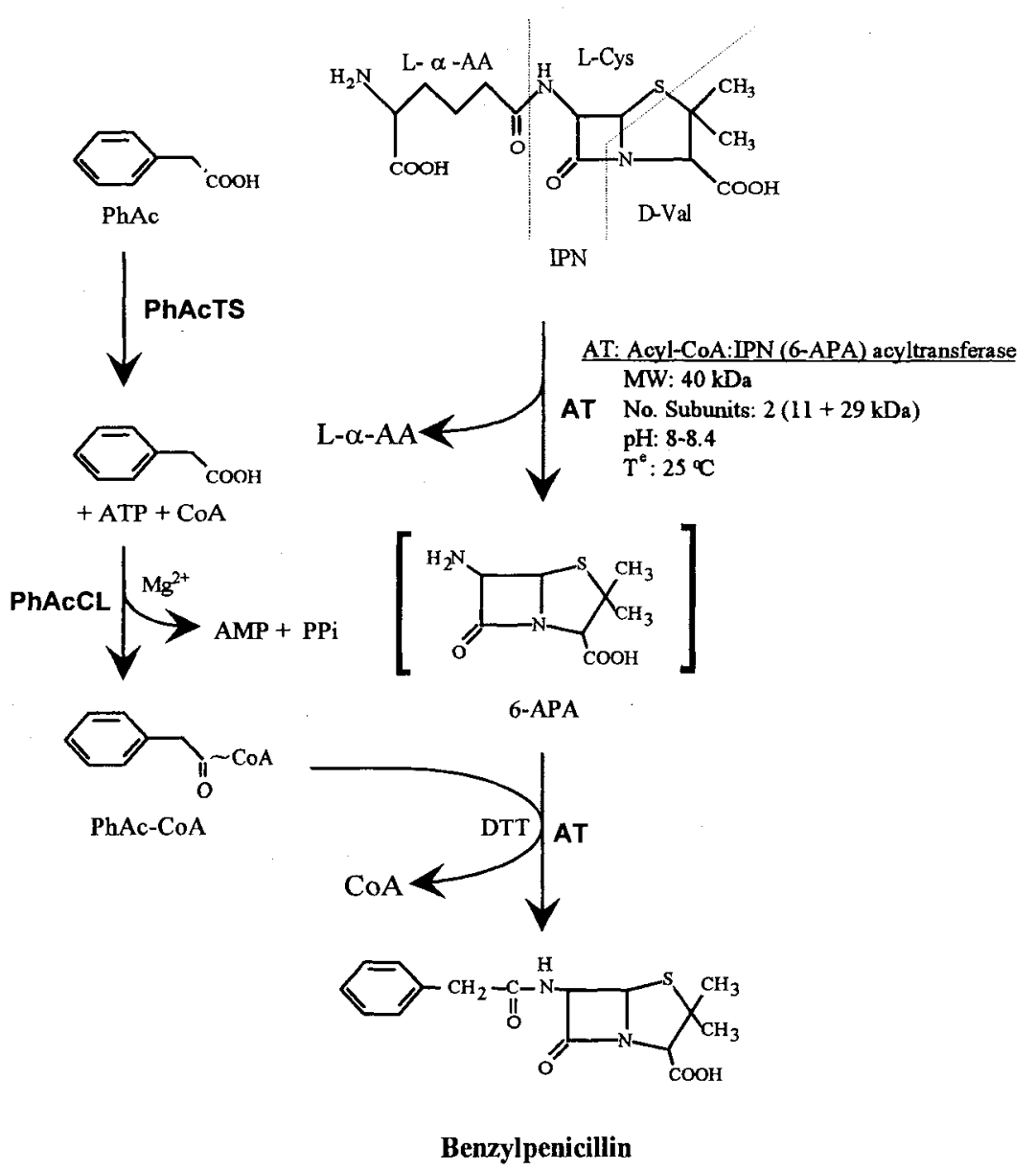

IPN, Isopenicillin N; PhAc, phenylacetic acid; L- $\alpha$-AA, L- $\alpha$-aminoadipic acid; PhAcCL, phenylacetyl-CoA ligase; PhAc-CoA, phenylacetyl-CoA; 6-APA, 6-aminopenicillanic acid; PhAcTS, phenylacetic acid transport system and AT, acyl-CoA-IPN(6-APA)-acyltransferase.

(Strasbourg, France); Merck (Darmstadt, Germany) or Sigma Chemical Co. (St. Louis, Mo. U.S.A.).

$\left[1-{ }^{14} \mathrm{C}\right]$ Phenylacetic acid $(24 \mathrm{mCi} / \mathrm{mmol})$ was from Sigma (U.S.A.), $\left[1-{ }^{14} \mathrm{C}\right]$ phenoxyacetic acid $(10 \mathrm{mCi} /$ mmol) was supplied by ICN (U.S.A.) and D- $\left[U_{-}{ }^{14} \mathrm{C}\right]-$ xylose $(76 \mathrm{mCi} / \mathrm{mmol})$ was from the Radiochemical Centre (Amersham, U.K.).

All other products used were of analytical quality or high-performance liquid chromatography (HPLC) grade.

\section{Strains}

The strains of $A$. nidulans used in this work and their origins are summarized in Table 1.

\section{Culture Media and Growth Conditions}

Spores of $A$. nidulans were obtained as previously reported $^{12)}$. Fungal cultures were carried out in 2,000$\mathrm{ml}$ Erlenmeyer flasks containing $400 \mathrm{ml}$ of minimal medium $(\mathrm{MM})^{13)}$ with the following composition (g/liter): $\mathrm{KH}_{2} \mathrm{PO}_{4}, 13.6 ;\left(\mathrm{NH}_{4}\right)_{2} \mathrm{SO}_{4}, 3 ; \mathrm{MgSO}_{4} \cdot 7 \mathrm{H}_{2} \mathrm{O}$, $0.3 ; \mathrm{FeSO}_{4} \cdot 5 \mathrm{H}_{2} \mathrm{O}, 0.001$. The medium was adjusted to
Table 1. Strains of $A$. nidulans used in this work.

\begin{tabular}{|c|c|c|}
\hline Mutant & Genotype & Source \\
\hline Wild type & $b i \mathrm{~A} 1$ & M. A. PeÑAlva (Madrid) \\
\hline facA 303 & $b i \mathrm{Al} ; f a c \mathrm{~A} 303$ & J. Clutterbuck (Glasgow) \\
\hline $\operatorname{creA}^{\mathrm{d}} 30$ & biAl; creA ${ }^{\mathrm{d}} 30$ & F.G.S.C. \\
\hline creB 15 & biAl; creB15 & F.G.S.C. \\
\hline creC27 & biAl; cre $\mathrm{C} 27 ; w \mathrm{~A} 7$ & F.G.S.C. \\
\hline$f p a \mathrm{D} 11$ & $\begin{array}{r}a d \mathrm{~F} 17 ; f p a \mathrm{D} 11 ; \\
\quad p a b a \mathrm{~A} 1 ; y \mathrm{~A} 2\end{array}$ & F.G.S.C. \\
\hline
\end{tabular}

F.G.S.C.: Fungal Genetics Stock Center. Department of Microbiology. University of Kansas Medical Center.

$\mathrm{pH} 7.0$ with $10 \mathrm{~m} \mathrm{KOH}$ and sterilized $\left(120^{\circ} \mathrm{C}, 15\right.$ minutes $)$. Glucose $(0.2 \% \mathrm{w} / \mathrm{v})$ or the different carbon sources used in the experiments were autoclaved separately. When required, the media were supplemented with the substances needed by each different mutant. Each Erlenmeyer flask was inoculated with $2 \times 10^{6}$ spores $/ \mathrm{ml}$ and incubated on a rotary shaker $(250 \mathrm{rpm})$ at $37^{\circ} \mathrm{C}$ for different times (between 0 and 40 hours). In some cases 
(to study the appearance of the PhAc transport system), $5 \mathrm{~mm} \mathrm{PhAc}$ was also supplied to the broth.

\section{Glucose Consumption}

Residual D-glucose was measured by the glucose oxidase method ${ }^{14)}$.

\section{Determination of $\mathrm{PhAc}$}

The content of $\left[1-{ }^{14} \mathrm{C}\right] \mathrm{PhAc}$ inside the cells was analyzed in cell-free extracts by HPLC (see below).

\section{HPLC Equipment and Chromatography Procedure}

Samples taken at different times from the uptake mixture were disrupted by sonication, quickly centrifuged ( $31000 \mathrm{~g}, 5$ minutes) and aliquots of $50 \mu \mathrm{l}$ were taken and analyzed using a high-performance liquid chromatograph (Spectra Physics SP8800) equipped with a variablewave-length ultraviolet/visible detector (SP8450), a integrator (SP4290) and a microparticulate $(10-\mu \mathrm{m}$ pore size) reverse-phase column (Nucleosil C-18 $250 \mathrm{~mm} \times$ $4.6 \mathrm{~mm}$ inner diameter: Phenomenex Laboratories U.S.A.). The mobile phase was 0.05 molar $\mathrm{HK}_{2} \mathrm{PO}_{4}$, $\mathrm{pH}$ $4-\mathrm{CH}_{3} \mathrm{CN}$ (99:1, by vol). The flow rate was set at $2.5 \mathrm{ml} /$ minute and the eluate was monitored at $254 \mathrm{~nm}$. Under these conditions the retention times for 2,5diOH-PhAc, 3,4-diOH-PhAc, 4-OH-PhAc, 2-OH-PhAc and PhAc were 6.6, 11.0, 20.3, 25.7 and 44.8 minutes, respectively. Phenylacetyl-CoA was also evaluated by HPLC as reported previously ${ }^{7)}$. In cell-free extracts we identified a single labelled compound with the retention time of phenylacetic acid. However, we neither found labelled hydroxy- derivatives of $\mathrm{PhAc}$ nor radioactive phenylacetyl-CoA.

\section{PhAc-uptake in A. nidulans}

Mycelia grown in the above media and conditions were harvested at the required time, filtered under vacuum and washed three times with sterile distilled water. Aliquots of $35 \mathrm{mg}$ (wet weight) (about $10 \mathrm{mg}$ of dry weight and equivalent to $2.5 \mathrm{mg}$ of protein) were resuspended in $25-\mathrm{ml}$ Erlenmeyer flasks containing $1.4 \mathrm{ml}$ of $0.05 \mathrm{M}$ phosphate buffer, $\mathrm{pH} 7.0$, and preincubated at $37^{\circ} \mathrm{C}$ for 5 minutes in a thermostatically controlled bath at 160 strokes/minute before adding PhAc $(51.4 \mu \mathrm{M}$ containing $0.05 \mu \mathrm{Ci}$ of labeled $\mathrm{PhAc})$ or PhOAc (56.4 $\mu \mathrm{M}$ containing $0.1 \mu \mathrm{Ci}$ of labeled $\mathrm{PhOAc}$ ). To calculate Vmax and $\mathrm{Km}$ values these concentrations were changed. Incubations were carried out for 30 seconds (or the required time); halted by adding 10 vol of water, rapidly filtered through Millipore filters $(0.45 \mu \mathrm{m}$ pore size $)$, and washed with $3 \times 10 \mathrm{ml}$ of sterile distilled water. The filters were dissolved in $10 \mathrm{ml}$ of scintillation fluid and counted as described $^{4)}$. To characterize this transport system, several effectors were added to the uptake mixture at $2.5 \mathrm{~mm}$ or at the indicated final concentration. In these cases, the effector tested was added 2 minutes before $\left[{ }^{14} \mathrm{C}\right] \mathrm{PhAc}$ or $\left[{ }^{14} \mathrm{C}\right] \mathrm{PhOAc}$. When arsenate was tested, the buffer employed was HCl-Tris (50 mm) pH 8.0.
Uptake is given as nmol of $\left[{ }^{14} \mathrm{C}\right] \mathrm{PhAc}$ (or $\left[{ }^{14} \mathrm{C}\right]$ $\mathrm{PhOAc} / \mathrm{minute} / \mathrm{mg}$ of protein or as nmol of $\left[{ }^{14} \mathrm{C}\right] \mathrm{PhAc}$ (or $\left.\left[{ }^{14} \mathrm{C}\right] \mathrm{PhOAc}\right) / \mathrm{mg}$ of protein) when different uptake periods were employed.

To study the eflux of $\mathrm{PhAc}$, the fungus was incubated in the presence of labelled $\mathrm{PhAc}$ for 5 minutes and at this time mycelia were harvested, washed and resuspended in the same buffer without PhAc. Measurements of the residual radioactivity were carried out for different times (between 0 and 30 minutes).

\section{PhAc-transport System Induction Experiments}

$A$. nidulans was cultured in the above medium and conditions and when glucose was exhausted (14 hours), mycelia were starved for a further 2 hours and then $5 \mathrm{~mm}$ $\mathrm{PhAc}$ (or $5 \mathrm{~mm} \mathrm{PhOAc}$ ) was added. The appearance of the PhAc transport system was measured at 90 minutes intervals. The effect of different molecules on the induction of this transport system was analyzed by adding the required compound to the minimal medium. In this kind of experiment, $A$. nidulans was grown in 2 liter-Erlenmeyer flasks containing $400 \mathrm{ml}$ of the same medium (see above). When glucose was exhausted, cells were harvested, washed, and $0.5 \mathrm{~g}$ of wet mycelia were transferred to $250 \mathrm{ml}$-Erlenmeyer flasks containing $50 \mathrm{ml}$ of $\mathrm{MM}$ and incubated at $37^{\circ} \mathrm{C}$ for 2 hours. At this time, $\mathrm{PhAc}$ (or other inducers) as well as different carbon sources were added. In all cases, the quantity of effector was equivalent, in carbon concentration, to $5 \mathrm{~mm}$ glucose.

\section{Results and Discussion}

\section{Phenylacetic Acid Transport System of Aspergillus nidulans}

Addition of $5 \mathrm{~mm}$ PhAc to $A$. nidulans cultures starved of a carbon source elicited a strong uptake of PhAc (Fig. 2). In cultures containing a mixture of glucose and $\mathrm{PhAc}$,

Fig. 2. Time-course of appearance of $\mathrm{PhAc}(\triangle)$ and PhOAc (ם) transport system; growth $(\nabla)$, glucose $(\nabla)$ and PhAc consumption ( $)$ in $A$. nidulans cultured in $\mathrm{MM}$.

Arrow indicates the time at which $\left[1-{ }^{14} \mathrm{C}\right] \mathrm{PhAc}$ was added.

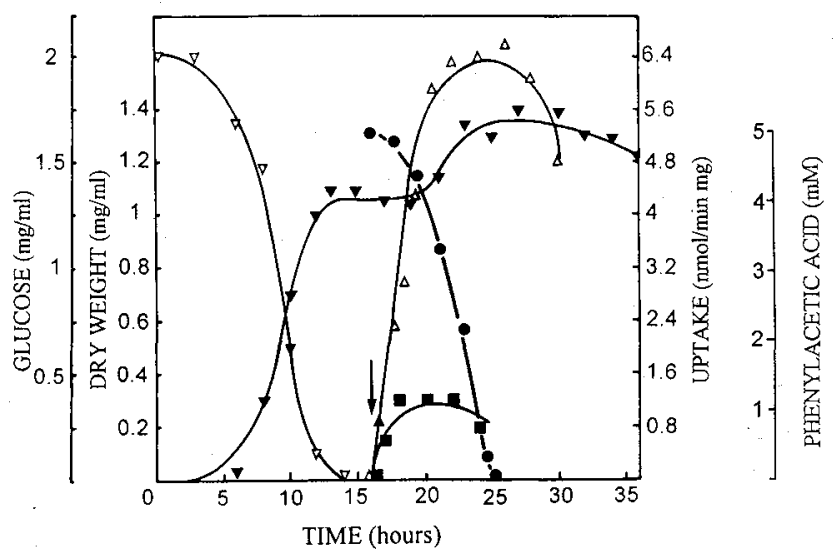


Fig. 3. Effect of different pH values on active transport (top) and passive diffusion (bottom) of PhAc (a). Assay of PhAc transport system at different temperatures (b); at different times (c); kinetics of PhAc-transport (1/v $v s .1 / \mathrm{s})$ (d); and kinetics of the PhOAc-transport system (1/v vs. 1/s) (e).
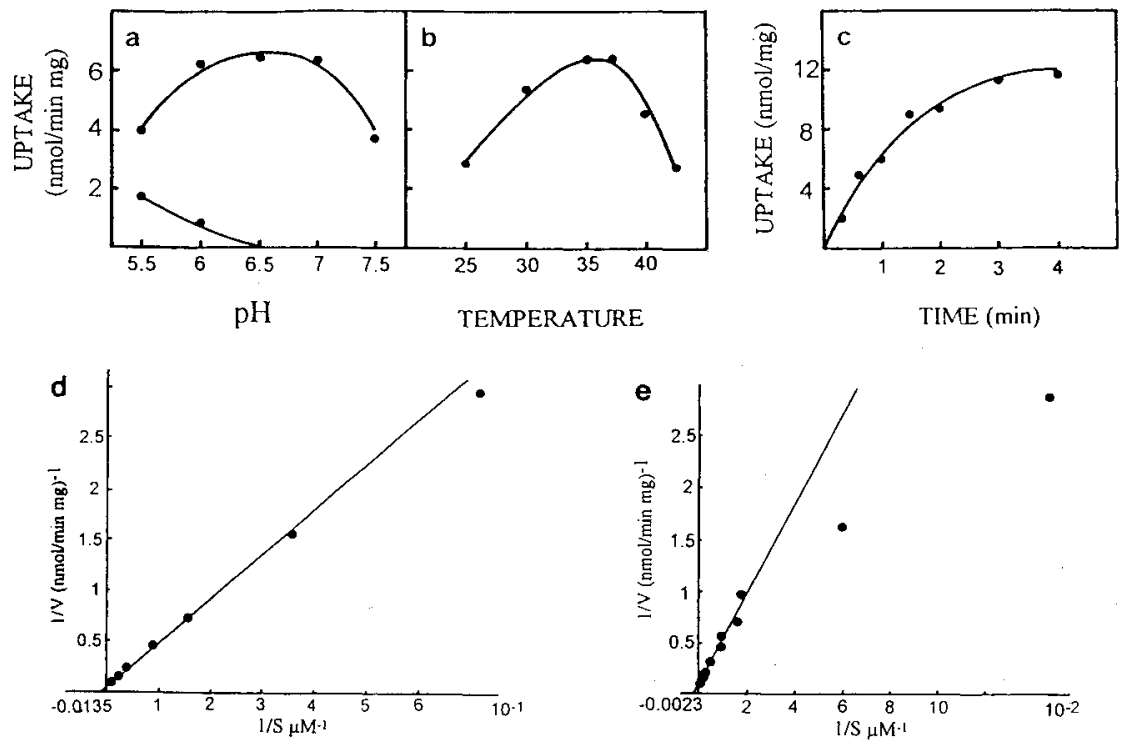

PhAc was not taken up until glucose had been exhausted, indicating that the sugar prevents induction of this uptake system. We therefore made cultures under controlled conditions in which glucose exhaustion would occur at 14 hours after inoculation and routinely induced the $\mathrm{PhAc}$ transport system by adding $5 \mathrm{~mm}$ PhAc after 16 hours of growth (see Fig. 2). Under these conditions and when $\mathrm{PhAc}$ was used as the carbon source, uptake was very efficient as shown by the resulting increase in mycelial dry weight (Fig. 2). The phenylacetic acid transport system thus induced was also able to transport PhOAc, although with lower efficiency $(20 \%)$ than for PhAc (see Fig. 2).

Maximal uptake rates were observed in $50 \mathrm{~mm}$ phosphate buffer, $\mathrm{pH} 7.0$ at $37^{\circ} \mathrm{C}$. Under these conditions, the $K m$ values were $74 \mu \mathrm{M}$ for $\mathrm{PhAc}$ and $425 \mu \mathrm{M}$ for PhOAc (see Fig. 3). At pH values lower than 5.5, a passive influx was observed in non-induced mycelia (see Fig. 3a) but this could not be seen when $\mathrm{pH}$ values were higher. Similar results have been reported for the penicillin producer $P$. chrysogenum Wis $54-1255^{4)}$. PhOAc also induced a PhAc uptake system (see below), although in this case the uptake rates were lower (see Table 2). The similar properties of PhAc uptake elicited by both of these aromatic compounds (see below) strongly suggests that both induce the same transport system, even though PhOAc cannot be utilised by the fungus as a carbon source and therefore represents a gratuitous inducer.

Table 2. Induction of the PhAc transport system in $A$. nidulans by different phenylderivatives.

\begin{tabular}{|c|c|c|}
\hline Compound tested & Growth & $\begin{array}{c}\text { Relative } \\
\text { uptake } \\
\text { capacity }(\%)\end{array}$ \\
\hline Phenylacetic acid & + & 100 \\
\hline 2-Hydroxyphenylacetic acid & + & 26 \\
\hline 3-Hydroxyphenylacetic acid & + & 40 \\
\hline 4-Hydroxyphenylacetic acid & + & 60 \\
\hline 2-Cl-phenylacetic acid & - & 59 \\
\hline 3-Cl-phenylacetic acid & - & 15 \\
\hline 4-Cl-phenylacetic acid & - & 23 \\
\hline 2-Methylphenylacetic acid & - & 36 \\
\hline 3-Methylphenylacetic acid & - & 65 \\
\hline 4-Methylphenylacetic acid & - & 75 \\
\hline Phenoxyacetic acid & - & 23 \\
\hline 3-Phenylpropionic acid & + & ND \\
\hline $\begin{array}{l}\text { 3-(2-Hydroxy)phenylpropionic } \\
\text { acid }\end{array}$ & + & ND \\
\hline $\begin{array}{l}\text { 3-(3-Hydroxy)phenylpropionic } \\
\text { acid }\end{array}$ & + & $\mathrm{ND}$ \\
\hline $\begin{array}{l}\text { 3-(4-Hydroxy)phenylpropionic } \\
\text { acid }\end{array}$ & + & ND \\
\hline 3-Phenoxypropionic acid & - & ND \\
\hline 4-Phenylbutyric acid & + & ND \\
\hline 4-Phenoxybutyric acid & + & ND \\
\hline Phenylalanine & + & ND \\
\hline Tyrosine & + & ND \\
\hline
\end{tabular}

In this table and in the following ones, $100 \%$ corresponds to $5.48 \mathrm{nmol} / \mathrm{minute} / \mathrm{mg}$ dry weight and all the data are the average of three different determinations. $(+)$ or $(-)$ growth indicates that $A$. nidulans is able $(+)$ or unable $(-)$ to use this compound as the sole carbon source. ND: Not detected. 
Table 3. Effect of different molecules on the uptake of PhAc by A. nidulans.

\begin{tabular}{lc|lc}
\hline \multicolumn{1}{c}{ Compound } & $\begin{array}{c}\text { PhAc } \\
\text { uptake } \\
(\%)\end{array}$ & \multicolumn{1}{c}{ Compound } & $\begin{array}{c}\text { PhAc } \\
\text { uptake } \\
(\%)\end{array}$ \\
\hline Control (without addition) & 100 & 3-Phenylpropionic acid & 7 \\
2-Hydroxyphenylacetic acid & 17 & 3-(2-Hydroxy)phenylpropionic acid & 39 \\
3-Hydroxyphenylacetic acid & 17 & 3-(3-Hydroxy)phenylpropionic acid & 35 \\
4-Hydroxyphenylacetic acid & 21 & 3-(4-Hydroxy)phenylpropionic acid & 10 \\
2-Methylphenylacetic acid & 38 & 2-Phenylpropionic acid & 70 \\
3-Methylphenylacetic acid & 9 & 3-Phenoxypropionic acid & 66 \\
4-Methylphenylacetic acid & 13 & 4-Phenylbutyric acid & 26 \\
2-Methoxyphenylacetic acid & 85 & 2-Phenylbutyric acid & 30 \\
3-Methoxyphenylacetic acid & 38 & 4-Phenoxybutyric acid & 64 \\
4-Methoxyphenylacetic acid & 40 & 2-Phenoxybutyric acid & 40 \\
Phenoxyacetic acid & 19 & Phenol & 56 \\
Benzoic acid & 40 & 2-Hydroxyphenol & 81 \\
2-Hydroxybenzoic acid & 83 & 3-Hydroxyphenol & 78 \\
2-Aminobenzoic acid & 75 & 4-Hydroxyphenol & 81 \\
4-Aminobenzoic acid & 50 & & \\
\hline
\end{tabular}

All compounds were tested at $2.5 \mathrm{~mm}$.

\section{Induction Specificity}

A. nidulans was grown in glucose minimal medium until the sugar had been exhausted, and then mycelia were washed and transferred to several media containing different aromatic compounds to test their ability to induce the PhAc uptake system. The highest levels of induction were obtained with PhAc, 3- and 4-methyl$\mathrm{PhAc}$ and 4-hydroxy-PhAc (Table 2). Several $\mathrm{Cl}$ - and methyl-derivatives were also able to induce uptake to different extents although they were not metabolised (Table 2). Interestingly, neither phenylpropionate (or hydroxy-derivatives) nor phenylbutyrate, which are used by the fungus as carbon sources, were able to induce the system, indicating a strong specificity for the acetyl moiety of PhAc. Conversely, however, 4-phenylbutyrate strongly induced the $P$. chrysogenum PhAc uptake system $^{5}$.

It is worth noting that Phe or Tyr did not act as inducers of the PheAc transport system (Table 2), suggesting that the physiological role of this uptake is not to transport the structurally-related aromatic amino acids. Indeed, a mutation ( $f p a$ D11, see Table 1) preventing Phe uptake ${ }^{15)}$ has no effect on the induction of PhAc transport system, and Phe or Tyr are not recognised by this uptake system (see below).

To test the ability of this PhAc uptake system to recognize different compounds, we used $\mathrm{PhAc}$-inducedmycelia in competition experiments with ${ }^{14} \mathrm{C}-\mathrm{PhAc}$ and an excess of the relevant compound. Table 3 shows that although different aromatic compounds inhibit ${ }^{14} \mathrm{C}$ PhAc uptake to different extents, indicating that the
Table 4. Effect of different sugars, amino acids and metabolic intermediates on phenylacetic acid transport system (PhAcTS) of $A$. nidulans

\begin{tabular}{lc|lc}
\hline Compound & $\begin{array}{c}\text { PhAc } \\
\text { uptake } \\
(\%)\end{array}$ & Compound & $\begin{array}{c}\text { PhAc } \\
\text { uptake } \\
(\%)\end{array}$ \\
\hline Control & 100 & Oxalacetic acid & 101 \\
(without addition) & & Arginine & 106 \\
Glucose & 91 & Aspartic acid & 97 \\
Fructose & 91 & Asparagine & 102 \\
Xylose & 39 & Glutamic acid & 100 \\
Sucrose & 98 & Glutamine & 113 \\
Lactose & 81 & Lysine & 104 \\
Glycerol & 86 & Tyrosine & 103 \\
Lactic acid & 89 & Phenylalanine & 93 \\
Acetic acid & 80 & Valine & 105 \\
Citric acid & 100 & Cysteine & 120 \\
\hline
\end{tabular}

All effectors were tested at $2.5 \mathrm{~mm}$.

uptake system is mediated by a protein and does not correspond to a passive diffusion mechanism ${ }^{8)}$, the uptake system is highly specific for PhAc. The highest inhibitions were observed with 3-phenylpropionic acid, 3-methyl PhAc, and 3(4-hydroxy)phenylpropionic acid. Interestingly, neither Phe nor Tyr were able to compete with PhAc uptake (Table 4). This was also the case for a number of amino acids, sugars (glucose, fructose, sucrose, lactose), glycerol and acids (acetic, lactic and TCA intermediates), with the exception of xylose, which competed with PhAc to a significant extent (61\%) (Table 4). However, mycelia induced with PhAc were unable to transport $\mathrm{D}-\left[U-{ }^{14} \mathrm{C}\right] \mathrm{xylose}$ and mycelia grown in D-xylose $(0.2 \% \mathrm{w} / \mathrm{v})$ as the sole carbon source were un- 
able to transport PhAc (data not shown).

\section{Effect of Different Reagents and Metabolic}

Inhibitors on the PhAc Transport System

The effects caused by different monothiols (MSH, GSH) and dithiols (DTT, GSSG) on the PhAc transport system were studied (see Table 5). None of them had any significant effect on the rate of transport, suggesting that an extracellular environment containing reduced thiols might not be necessary for the uptake of $\mathrm{PhAc}^{16)}$. However, the thiol-modifying reagents $N$-ethylmaleimide (NEM), 5,5'-dithiobis nitrobenzoic acid (DTNB) and iodoacetate inhibited PhAc uptake (51, 70 and 65\%, respectively). These data indicate that reduced thiol groups are essential for the catalytic function of this transport system ${ }^{4,7,17,18}$. When metabolic inhibitors were tested, we observed that cyanide and azide decreased the uptake of PhAc (65 and 84\%, respectively) and that uptake was also inhibited when uncoupling agents (protonophores), such as carbonylcyanide-p-trifluoromethoxyphenylhydrazone (FCCP) (83\%), 2,4-dinitrophenol $(68 \%)$ and 4-nitrophenol $(73 \%)$ were tested. These results suggest that the $\mathrm{PhAc}$ transport system is an energy-dependent system probably mediated by $\mathrm{a} \mathrm{H}^{+}$ gradient. Similar results have been reported for the transport of different molecules in several other biological systems $^{7,16 \sim 19)}$. It is interesting to note the lack of effect caused by arsenate, even when this compound was tested at $10 \mathrm{~mm}$ (final concentration) in the absence of phosphate (see Materials and Methods) indicating that it is not energized by a phosphorylated compound.

Table 5. Effect of uncouplers, metabolic inhibitors, thiolcontaining and thiol-modifying reagents on the PhAcTS in A. nidulans.

\begin{tabular}{lc}
\multicolumn{1}{c}{ Compound } & $\begin{array}{c}\text { PhAc uptake } \\
(\%)\end{array}$ \\
\hline Control without addition & 100 \\
$\beta$-Mercaptoethanol (MSH) & 91 \\
Dithiothreitol (DTT) & 96 \\
Oxidized glutathione (GSSG) & 103 \\
Reduced glutathione (GSH) & 104 \\
$N$-Ethylmaleimide & 49 \\
5,5-Dithiobisnitrobenzoic acid (DTNB) & 30 \\
Iodoacetate & 36 \\
Potassium cyanide & 35 \\
Sodium azide & 16 \\
FCCP (100 $\mu$ M) & 17 \\
2,4-Dinitrophenol (1 mM) & 32 \\
4-Nitrophenol (1 mM) & 27 \\
2-Nitrophenol (1 mM) & 91 \\
Arsenate (10 mm) & 92 \\
\hline
\end{tabular}

All compounds were tested at $2.5 \mathrm{~mm}$ or at the concentration indicated between bracketts.
Additional proof that PhAc-transport is an active process arose from the study of the $\left[1-{ }^{14} \mathrm{C}\right] \mathrm{PhAc}$ eflux (see Materials). No efflux of labelled PhAc was observed even after 30 minutes of incubation. It could be expected that $\left[1-{ }^{14} \mathrm{C}\right] \mathrm{PhAc}$, which was detected as free acid inside the cells (see Materials), would be released to the medium if uptake were mediated by passive diffusion.

\section{Regulation by Carbon Sources of Induction of PhAc Uptake}

Addition of D-glucose, D-fructose, D-xylose, L-fructose or glycerol at the time of $\mathrm{PhAc}$ induction prevented the appearance of the $\mathrm{PhAc}$ transport system, while addition of pyruvate, oxaloacetate or citrate had no effect on induction (Fig. 4). As indicated above, the fact that the addition of phenylacetate before glucose had been exhausted from the cultures did not result in induction of the PhAc transport system, suggested that induction might be regulated by carbon catabolite repression ${ }^{20}$. However, the fact that glycerol (a derepressing carbon source in creA-mediated carbon catabolite repression) prevented induction, suggested the existence of a creAindependent mode of carbon regulation. A similar effect of glycerol has been described in $P$. chrysogenum for both PhAc transport and penicillin biosynthesis ${ }^{21)}$. In $A$. nidulans, Espeso and coworkers have shown the existence of a creA-independent mechanism that negatively regulates the transcription of $I p n \mathrm{~A}$, a penicillin biosynthetic gene ${ }^{22)}$. This negative regulatory circuit, is also independent of cre $\mathrm{B}$ and $c r e \mathrm{C}$, two genes possibly encoding membrane proteins, whose mutation results in carbon catabolite derepression of several enzymes which are under catabolic repression in the wild type ${ }^{23,24)}$.

Fig. 4. Effect of different carbon sources on the induction of PhAc in A. nidulans.

(a) Control without addition (•), +D-fructose (A), +D-glucose $(\triangle)$, +D-mannose $(\nabla)$ and +D-xylose (a); (b)

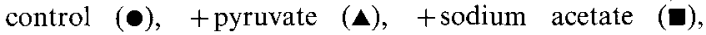
+potassium acetate $(\boldsymbol{\nabla}),+$ ammonium acetate $(\Delta)$, + citrate $(\nabla)$ and oxalacetate $(\square)$; (c) control $(\bullet)$, + lactose $(\square),+$ glycerol $(\boldsymbol{\square}),+$ sucrose $(\Delta)$, and + maltose $(\nabla)$.

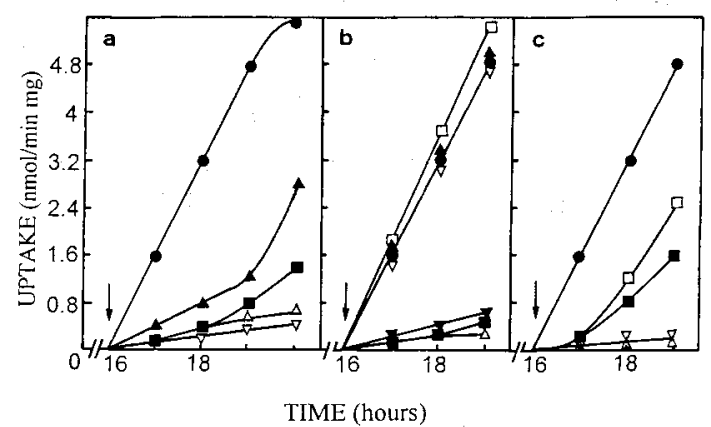


Table 6. Uptake of PhAc by different mutants of A. nidulans.

\begin{tabular}{lcccc}
\hline & \multicolumn{4}{c}{ Carbon source } \\
\cline { 2 - 5 } Strain & - & PhAc & $\begin{array}{c}\text { PhAc }+ \\
\text { glucose }\end{array}$ & $\begin{array}{l}\text { PhAc }+ \\
\text { glycerol }\end{array}$ \\
\hline Wild type & 0.4 & 13.7 & 0.6 & 2.3 \\
creA $^{\mathrm{d}}$ 30 & 0.5 & 13.9 & 1.3 & 2.9 \\
creB 15 & 1.1 & 11.9 & 7.2 & 8.3 \\
creC 27 & 0.6 & 10.2 & 4.6 & 5.6 \\
\hline
\end{tabular}

$\mathrm{PhAc}$ uptake is given as $\mathrm{nmol} / \mathrm{minute} / 10 \mathrm{mg}$ dry weight. Mutants cre $\mathrm{A}^{\mathrm{d}} 30$, cre $\mathrm{B} 15$ and $\mathrm{creC} 27$ are strains of A. nidulans altered in catabolic repression (derepressed).

It has been suggested that the cre $\mathrm{B} 15$ and $\operatorname{cre} \mathrm{C} 27$ gene products are not true transcriptional repressors and that mutants carrying this kind of mutation could be altered in membrane permeability and hence in different transport systems. If this were the case, the uptake of the molecule responsible for catabolic repression could be diminished and, therefore, not effect could be caused since the repressor cannot be taken-up ${ }^{25)}$. However, no alterations in glucose uptake have been found in these mutants ${ }^{23 \sim 26)}$. Moreover, we did not observe any significant differences in mycelia growth when the fungus was cultured in the presence of glucose and neither were alterations observed in glucose uptake (in a concentration range between $17 \mu \mathrm{M}$ and $1 \mathrm{~mm}$ ) or in $\mathrm{PhAc}$ transport (data not shown). Table 6 indicates that the repression of the PhAc uptake is not mediated by the creA gene product, since the derepressed mutant (cre $\left.\mathrm{A}^{\mathrm{d}} 30\right)$ can be regulated, like the wild type, by glucose and glycerol, suggesting the involvement of a different gene ( $\mathrm{creB}$ or $(r e \mathrm{C}$ ) in the control of this system. Thus, mutants $c r e \mathrm{~B}$ and $c r e \mathrm{C}$ are able to induce PATS even in the presence of a concentration of glucose which repressed the induction of the transport system in the wild type and in cre $\mathrm{A}^{\mathrm{d}} 30$ mutant (see Table 6). A similar hypothesis was proposed, in pioneering work, by HYNES and KELLY studying pleiotropic mutants of $A$. nidulans altered in carbon metabolism ${ }^{24)}$.

Acetate strongly repressed PhAc uptake (see Fig. 4). A negative role of acetyl-CoA on sugar transport has been previously described by ROMANO and KORNBERG ${ }^{27)}$, and indeed we have previously presented evidence pointing to the repression of PhAc uptake by acetyl-CoA in $P$. chrysogenum ${ }^{28)}$. If the negative effect of acetate were indeed mediated through acetyl-CoA, the absence of acetyl-CoA synthetase would prevent this effect. Table 7 shows that this is in fact the case. The addition of acetate abolished $\mathrm{PhAc}$ induction with the wild type
Table 7. Uptake of $\mathrm{PhAc}$ by the facA 303 mutant of A. nidulans.

\begin{tabular}{lcc}
\hline \multirow{2}{*}{ Carbon source } & \multicolumn{2}{c}{ Strain } \\
\cline { 2 - 3 } & Wild type & facA 303 \\
\hline- & 0.4 & 0.3 \\
PhAc & 13.7 & 12.3 \\
PhAc + glucose & 0.5 & 0.4 \\
PhAc + glycerol & 2.1 & 1.1 \\
PhAc + acetate & 0.6 & 12.5 \\
PhAc +hexanoate & 1.2 & 0.2 \\
\hline
\end{tabular}

facA 303 mutant is defective in acetyl-CoA synthetase. $\mathrm{PhAc}$ uptake is given as $\mathrm{nmol} /$ minute/ $/ 10 \mathrm{mg}$ dry weight.

strain, but had no effect with a facA 303-mutant strain (see Table 1) lacking in acetyl-CoA-synthetase ${ }^{29,30)}$. This strain is not a defective transport mutant since acetate is able to induce certain enzymes involved in it own catabolism (isocitrate lyase, acetamidase and other related enzymes) suggesting that it is taken up by the cells ${ }^{31}$. In this mutant, acetate is able to induce enzymes which are specifically produced in presence of acetate (like isocitrate lyase) ${ }^{29}$ but it is unable to synthesize those enzymes induced by acetyl-Co ${ }^{31)}$. The mutation had no effect when glucose, glycerol or hexanoate were added instead since their conversion to acetyl-CoA does not require acetyl-CoA synthetase. These results support our hypothesis that transition from primary (growth) to secondary metabolism (penicillin production and other events) could be mediated by either the intracellular pool of acetyl-CoA or by the acetyl-CoA/CoA ratio in these two fungi ${ }^{1,28)}$.

\section{Acknowledgments}

We thank N. S. D. SkINNER for revising the English version of the manuscript and R. SÁnCHEz Barbero for typing it. The work was supported by Grants from the Comision Interministerial de Ciencia y Tecnología (CICYT) Madrid, Spain (Grant BIO 96-0402) and the Junta de Castilla y León (Consejería de Cultura y Turismo). We thank M. A. Peñalva for some of the strains used in this work.

\section{References}

1) Luengo, J. M.: Recent advances in the enzymatic synthesis of penicillins. In Progress in Industrial Microbiology. Vol. 27, Eds., M. E. BUSHELl and U. GRÄFFE, pp. 315 332, Elsevier, Amsterdam, 1989

2) Luengo, J. M.: Enzymatic synthesis of hydrophobic penicillins. J. Antibiotics 48: 1195 1212, 1995

3) Hersbach, G. J. M.; C. P. Van der Beeck \& P. W. M. DIJCK: The penicillins: properties, biosynthesis and fermentation. Biotechnol. Ind. Antibiot. 22: 45 140, 1984 
4) Fernández-Cañón, J. M.; A. Reglero, H. MartínezBLANCO \& J. M. LuENGO: I. Uptake of phenylacetic acid by Penicillium chrysogenum Wis 54-1255: A critical regulatory point in benzylpenicillin biosynthesis. J. Antibiotics 42: 1389 1409, 1989

5) Fernández-Cañón, J. M; A. Reglero, H. MartínezBlanco, M. A. Ferrero \& J. M. Luengo: II. Phenylacetic acid transport system in Penicillium chrysogenum Wis 54-1255. Molecular specificity of its induction. J. Antibiotics 42: 1410 1415, 1989

6) Tan, K. P. I.; J. M. Fernández-Cañón, A. Reglero \& J. M. LUENGO: Effect of analogues of phenylacetic acid (PA) on the PA transport system in Penicillium chrysogenum strains H1107 and M223. Appl. Microbiol. Biotechnol. 40: 113 116, 1993

7) Schleissner, C.; E. R. Olivera, M. FernándezVALVERde \& J. M. Luengo: Aerobic catabolism of phenylacetic acid in Pseudomonas putida U: Biochemical characterization of a specific phenylacetic acid transport system and formal demonstration that phenylacetyl-CoA is a catabolic intermediate. J. Bacteriol. 176: $7667 \sim 7676$, 1994

8) Hillenga, D. J.; H. J. M. Versantyoort, S. Van der Molen, A. J. M. Driessen \& W. N. Konings: Penicillium chrysogenum takes up the penicillin $\mathrm{G}$ precursor phenylacetic acid by passive diffusion. Appl. Environ. Microbiol. 61: $2589 \sim 2595,1995$

9) Eriksen, S. H.; B. Jensen, I. Schneider, S. KaAsGaArd \& J. OlsEn: Uptake of phenoxyacetic acid by Penicillium chrysogenum. Appl. Microbiol. Biotechnol. 42: 945 950, 1995

10) Hunter, D. R. \& I. M. Segel: Effect of weck acids on amino acid transport by Penicillium chrysogenum: evidence for a proton of charge gradient as the driving force. J. Bacteriol. 113: 1184 1192, 1973

11) HaRwood, C. S.; N. N. Nichols, M.-K. Kim, J. L. DitTy \& R. E. PARALES: Identification of the pcaRKF gene cluster from Pseudomonas putida: Involvement in chemotaxis, biodegradation, and transport of 4-hydroxybenzoate. J. Bacteriol. 176: 6479 6488, 1994

12) Cove, D. J.: The induction and repression of nitrate reductase in the fungus Aspergillus nidulans. Biochim. Biophys. Acta 113: $51 \sim 56,1966$

13) Miller, J. H: In Experiments in Molecular Genetics. p. 431, Cold Spring Harbor Laboratory, New York, 1972

14) Bergmeyer, H. V. \& E. Bernt: In Methods of Enzymatic Analysis. Vol. 3, Ed., H. U. BergmeYER, pp. 1205 1212, Academic Press, New York, 1984

15) SinHA, U.: Genetic control of the uptake of amino acids in A. nidulans. Genetics 62: 495 505, 1969

16) Morgan, M. S.; R. M. Darrow, M. A. NafZ \& P. T. VARANDANI: Participation of cellular thiol/dishulphide groups in the uptake, degradation and bioactivity of insuline in primary cultures of rat hepatocytes. Biochem. J. 225: $349 \sim 356,1985$
17) Miñambres, B.; A. Reglero \& J. M. Luengo: Characterization of an inducible transport system for glycerol in Streptomyces clavuligerus. Repression by L-serine. J. Antibiotics 45: 269 277, 1992

18) Rodríguez-Aparicio, L. B.; A. Reglero \& J. M. Luengo: Uptake of $\mathrm{N}$-acetylneuraminic acid by Escherichia coli K-235. Biochem. J. 246: $287 \sim 294,1987$

19) Hunter, D. R. \& I. M. Segel: Acidic and basic amino acid transport systems of Penicillium chrysogenum. Arch Biochem. Biophys. 144: 168 185, 1971

20) Bailey, C. \& H. N. Arst, Jr.: Carbon catabolite repression in Aspergillus nidulans. Eur. J. Biochem. 51: 573 577, 1975

21) Martínez-Blanco, H.; A. Reglero, M. A. Ferrero, J. M. Fernández-CAÑón \& J. M. LuENGo: III. Repression of phenylacetic acid transport system in Penicillium chrysogenum Wis $54-1255$ by free amino acids and ammonium salts. J. Antibiotics 42: 1416 1423, 1989

22) Espeso, E.; J. Tilburn, H. N. Arst, Jr. \& M. A. Peñalva: $\mathrm{pH}$ regulation is a major determinant in the expression of a fungal penicillin biosynthetic gene. EMBO J. 10: $3947 \sim 3956,1993$

23) Espeso, E.; J. M. Fernández-Cañón \& M. A. Peñalva: Carbon regulation of penicillin biosynthesis in Aspergillus nidulans: A minor effect of mutations in cre $\mathrm{B}$ and cre $\mathrm{C}$. FEMS Microbiol. Letters 126: 63 68, 1995

24) Hynes, M. J. \& J. M. Kelly: Pleiotropic mutants of Aspergillus nidulans altered in carbon metabolism. Mol. Gen. Genet 156: 193 204, 1977

25) ARsT, H. N. Jr.: Aspects of the control of the gene expresion in fungi. In Genetics as a tool in Microbiology. Eds., S. W. Glover and D. A. Hopdwood, Society for General Microbiol. Cambridge University Press Symposium 31, pp. $131 \sim 160,1981$

26) Brownlee, A. G. \& H. N. Arst, Jr.: Quench correction of incorporated ${ }^{14} \mathrm{C}$ in Aspergillus nidulans counted in filters discs. J. Microbiol. Methods 2: 83 91, 1984

27) Romano, A. H. \& H. L. KornberG: Regulation of sugar utilization by Aspergillus nidulans. Biochim. Biophys. Acta 158: 491 493, 1968

28) Martínez-Blanco, H.; A. Reglero, M. FernándezValverde, M. A. Ferrero, M. A. Moreno, M. A. Peñalva \& J. M. LuENGo: Isolation and characterization of the acetyl-CoA synthetase from Penicillium chrysogenum. J. Biol. Chem. 267: 5474 5481, 1992

29) ApIRION, D.: The two way selection of mutants and revertants in respect of acetate utilization and resistance to fluoro-acetate in Aspergillus nidulans. Genet. Res. 6: $317 \sim 329,1965$

30) Armitt, S.; W. MCCuleough \& C. F. Roberts: Analysis of acetate non-utilizing ( $a c u$ ) mutants in Aspergillus nidulans. J. Gen. Microbiol. 92: 263 282, 1976

31) HYNES, M. J.: Induction of the acetamidase of Aspergillus nidulans by acetate metabolism. J. Bacteriol. 131: $770 \sim$ 775,1977 